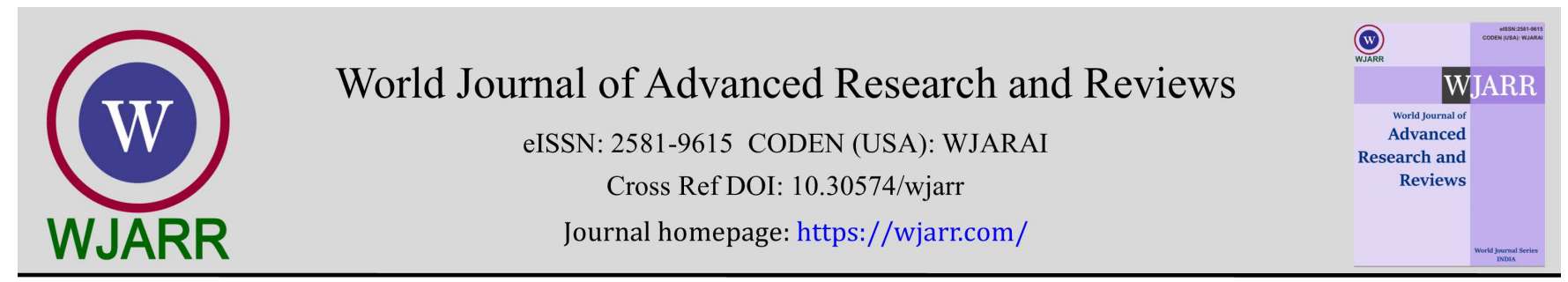

(REVIEW ARTICLE)

Check for updates

\title{
Public health fault lines in the fight against COVID-19: Lessons from Africa
}

\author{
Saikou Omar Sillah ${ }^{1,2 *}$ and Xu Yihua ${ }^{2}$ \\ ${ }^{1}$ The Gambia College, School of Public Health. \\ ${ }^{2}$ Department of Epidemiology and Biostatistics, School of Public Health, Tongji Medical College of Huazhong University of \\ Science and Technology, Wuhan.
}

World Journal of Advanced Research and Reviews, 2021, 11(02), 260-262

Publication history: Received on 13 July 2021; revised on 18 August 2021; accepted on 20 August 2021

Article DOI: https://doi.org/10.30574/wjarr.2021.11.2.0386

\begin{abstract}
On 31st December 2019, the World Health Organization (WHO) was notified of a cluster of cases of pneumonia of unknown cause detected in the Wuhan, Hubei Province of China which eventually was named to be the Corona virus disease. In response to the rapid spread of the virus, WHO declared it a public health emergency of international concern (PHEIC) on 30th January, 2020. As per the quest to recharge the COVID-19 response power, there is seemingly little or no tangible plans to help permanently reorient Africa's health care system. In the wake of widespread vaccine nationalism, donor countries continue to secure large quantities of vaccines from developers and manufacturers, causing global disparity in access to COVID-19 vaccines.
\end{abstract}

Keywords: COVID-19 Pandemic; Africa; Lessons, Public health

\section{Background}

On 31st December 2019, the World Health Organization (WHO) was notified of a cluster of cases of pneumonia of unknown cause detected in the Wuhan, Hubei Province of China which eventually was named to be the Corona virus disease (COVID-19) [1]. The outbreak poses a serious challenge to Africa's socio-economic and political struggle [2]. The systemic fault lines of public policy are glaringly evident across the continent because of the COVID -19 pandemic. The world became troubled within no time, with the marginalized becoming visible in even rich, global core economies. Western governments started battling with their own outbreaks, leaving African nations largely on their own.

\section{Discussion}

In response to the rapid spread of the virus, WHO declared it a public health emergency of international concern (PHEIC) on $30^{\text {th }}$ January, 2020? Subsequently, the epidemic was declared pandemic by the WHO on the 11 th of March 2020 [1]. Western governments started battling with their own outbreaks, leaving African nations largely on their own. Beyond the failure of meeting the three core public health functions, the COVID-19 pandemic has exposed the impacts of the inequalities faced by the continents health care system. Beside this, a bigger problem is the fact that Africa's health care power is grossly inadequate with limited capacity and capability to cater for the anticipated COVID19 cases. Isolation facilities further discourage symptomatic patients from seeking care [3]. In fact, a lot of households in the continent do not have access to basic facilities such as water and soap [4]. Self-isolation and lockdown in Africa further present additional challenges due to factors such as poor housing and congested settlements.

\footnotetext{
${ }^{*}$ Corresponding author: Saikou Omar Sillah

The Gambia College, School of Public Health; Department of Epidemiology and Biostatistics School of Public Health Tongji Medical College of Huazhong University of Science and Technology, Wuhan 
Africa still suffers limited laboratory capacity. Many labs have inadequate human and material resources, creating much more problems in the handling of COVID-19 test samples. With high numbers of tests received daily at these facilities, the dispatch time of results is delayed because the demand exceeds the capacity. Here, such delays have a serious consequence as possibly the current COVID-19 figures could be far lower than the true sum of infections [5]. As per the quest to recharge the COVID-19 response power, there is seemingly little or no tangible plans to help permanently reorient Africa's health care system. Figuratively, close to $56 \%$ of its urban population in camped in crowded and poor serviced slums. Again, it has been reported that only about $34 \%$ of the population have access to properly wash their hands. Diseases such as tuberculosis, malaria and HIV/AIDS continues to be recorded in Africa with the continent recognized to have the highest prevalence of these diseases [4]. In the wake of widespread vaccine nationalism, donor countries continue to secure large quantities of vaccines from developers and manufacturers, causing global disparity in access to COVID-19 vaccines. And with the current trends of international politics influenced by geographical factors surrounding procurement of vaccines, Africa has been disadvantaged and unable to maintain adequate supply for her people [6]. A significant number of the population remains unvaccinated.

In Zimbabwe, the wave of COVID-19 arrived when the country was suffocating a deteriorating health care power with very bad disease trends. Death trends showed that the population was still suffering infectious diseases such as TB, lung diseases and HIV/AIDS, with pockets of diarrheal conditions including nutritional deficiencies. The Gambia, a country with $48 \%$ poverty rate, the decision to choose an efficient and complete lockdown is never likely as the Government lacks resources to support the population. In Nigeria, it is evident that the country was caught off guard with the COVID19 outbreak due to widespread corruption. The healthcare system is dilapidated and weak for many years [9]

\section{Conclusion}

The challenge now is for Africa to Increase productivity that will support its public health power, economic diversification, and structural reforms. Africa will require the strategic production and retention of many highly skilled and employable graduates, particularly in key fields related to science and technology. It must also adjust its health financing power. Africa's clinicians should dual track the health care power and adjust its referral pathways, patient consultations and assessment guidelines to avoid mix and match diagnosis of disease events and commence aggressive networked laboratory surveillance in order to help better situate the covid-19 pandemic and enhance rapid and adequate response to the event.

\section{Compliance with ethical standards}

\section{Acknowledgments}

Appreciation goes to Prof. Dr. Oscar H. Franco, Adjunct Professor Harvard T.H. Chan School of Public Health, Harvard University for his technical support and inspiration to writing this paper as part of the Tongji Medical College Summer Program 2021 requirements.

\section{Disclosure of conflict of interest}

The authors declare that they have no conflict of interest. No commercial organization with a direct or indirect interest in the content of this study has conferred or will confer a benefit on the authors or any organization with which the authors are associated. This study has not previously been presented in any form.

\section{References}

[1] WHO. 2020. Emergency Diseases News Outbreak Item.

[2] Tusting LS, Bisanzio D, Alabaster G. Mapping changes in housing in sub-Saharan Africa from 2000 to 2015 . Nature. 2019; 568(7752): 391-4.

[3] Akpabio Akpabio, Utibe Effiong on. 25 May 2020

[4] Abhishek Mishra, "Africa and COVID-19: Impact, Response, and Challenges to Recovery," ORF Occasional Paper No. 275, September 2020, Observer Research Foundation.

[5] Antony Sguazzin and Janice Kew, "Most Ambitious Africa Program to Halt Virus Is Floundering," Bloomberg. 9 June 2020. 
[6] COVID-19 vaccines: the challenges of protecting africa's fragile regions By Sophie Desmidt and Ashley Neat. March 2021.

[7] Collet Dandara, Kevin Dzobo, and Shadreck Chirikure.OMICS: A Journal of Integrative Biology. Apr 2021; 209212.

[8] Tobiloba Oyejide Alex Omotosho, Oluwatomilayo Felicity Omotosho, Paul Bass and Yahya Njie COVID-19 challenges: The Gambia situation and probable solutions. World Journal of Advanced Research and Reviews. 2020; 07(03): 070-076.

[9] Anyanwu MU, Festus IJ, Nwobi OC, Jaja C-JI, Oguttu JW. A Perspective on Nigeria's Preparedness, Response and Challenges to Mitigating the Spread of COVID-19. Challenges. 2020; 11: 22. 